College Students in the Western World are Becoming Less Emotionally Intelligent: A Cross-Temporal Meta-Analysis of Trait Emotional Intelligence Mahreen Khan (School of Management, UNSW Business School, UNSW Sydney) Amirali Minbashian (School of Management, UNSW Business School, UNSW Sydney) Carolyn MacCann (School of Psychology, University of Sydney)

Running title: Trait Emotional Intelligence Over Time

Funding statement: This research was conducted as part of an Australian Research Council Discovery Project (DP150101158) funded by the Australian Government.

Conflict of interest disclosure: The authors have no conflicts of interest to disclose.

This is the peer reviewed version of the following article: Khan, M., Minbashian, A., MacCann, C. (In Press). College Students in the Western World are Becoming Less Emotionally Intelligent: A Cross-Temporal Meta-analysis of Trait Emotional Intelligence. Journal of Personality., which has been published in final form at DOI:10.1111/jopy.12643. This article may be used for non-commercial purposes in accordance with Wiley Terms and Conditions for Use of Self-Archived Versions. 


\begin{abstract}
Objective: Over the last two decades, Western society has undergone a marked cultural transformation characterised by rising individualism. Concurrently, the digital landscape has transformed through the rise of social media and smartphones. These factors have previously been implicated in changing individuals' attitudes, behaviour and interpersonal interactions. We investigated whether these societal changes have coincided with changes in trait emotional intelligence (EI) over the last 17 years in Western university students. Method: We examined this question using a cross-temporal meta-analysis $(k=70 ; N=16,917)$. Results: There was no change in overall trait EI; however, the trait EI domains "wellbeing," "self-control" and "emotionality" demonstrated significant decreases with time, after controlling for gender composition and between-country differences. Conclusion: We discuss these findings in relation to how they contribute to our understanding of trait EI, and how they add to the literature on how Western society is changing with time.
\end{abstract}

Keywords: emotional intelligence; meta-analysis; cross-temporal 


\section{College Students in the Western World are Becoming Less Emotionally Intelligent: A Cross-Temporal Meta-Analysis of Trait Emotional Intelligence}

The present study aims to investigate whether there are generational changes in individuals' emotional intelligence (EI). This may be the case because, in as little of a period as two decades, the cultural landscape of Western society has markedly transformed.

Neoliberal governance has increasingly fostered an environment characterised by competitive individualism. Concomitantly, the last decade witnessed the meteoric rise of social media such as Facebook and Snapchat. Social media has become so pervasive that in 2018 an estimated $69 \%$ of American adults reported using Facebook; of these individuals, 74\% visited Facebook daily (Twenge, Joiner, Rogers \& Martin, 2018). The rise of social media was facilitated through the ubiquitousness of personal smartphones - by $2018,95 \%$ of American adolescents had access to a smartphone (Anderson \& Jiang, 2018). These varying societallevel changes have been implicated in changing individuals' attitudes, behaviour and interpersonal interactions. As a consequence, there have been generational increases in personality traits such as self-esteem, assertiveness and narcissism (Gentile, Twenge \& Campbell, 2010; Twenge, 2001; Twenge, Konrath, Foster, Campbell \& Bushman, 2008). More troublingly, there have also been generational decreases in empathy and increases in depression and anxiety symptoms (Konrath, O’Brien \& Hsing, 2011; Twenge, Gentile, DeWall, Ma, Lacefield \& Schurtz, 2010; Booth, Sharma \& Leader, 2016).

Together, these societal-level changes may impact individuals' levels of EI. That is, generational differences in individualism and social media use may result in mean-level changes in EI. In this cross-temporal meta-analysis, our aim is to test whether trait EI (characterised by well-being, emotionality, self-control and sociability-related traits) among Western university students has changed over the last two decades. Addressing this issue will enable us to add to the body of literature on generational changes occurring in Western 
society (e.g., Gentile et al., 2010; Twenge, 2001; Twenge et al., 2008). Moreover, we will be able to indirectly provide evidence that cultural changes can impact EI - an antecedent that has largely been ignored by the existing literature.

In the following paragraphs, we start by outlining the various conceptualisations of EI, specifically focusing on trait EI. We then discuss how trait EI maps onto other personality frameworks, as this will help provide a more nuanced perspective for why trait EI is likely to change with time. Next, we discuss the various cultural changes that have occurred in Western society, and how these changes may be responsible for changes in trait EI. Finally, we outline the cross-temporal meta-analytic procedure and how it is suitable for assessing societal changes in individual difference variables.

\section{Trait EI}

EI researchers typically use measurement method to distinguish between two conceptualisations of EI: (1) ability EI, whereby emotion-related abilities are assessed using maximum-performance measures; and (2) trait EI, whereby emotion-related dispositions and self-perceptions are assessed using rating scales, most often self-reports (Petrides \& Furnham, 2001). These two measurement models of EI capture substantially different concepts, as there are only modest correlations between ability and trait scales of EI (e.g., $\rho=$ .12 to .26 in a meta-analysis; Joseph \& Newman, 2010).

A previous cross-temporal meta-analysis (Pietschnig \& Gittler, 2017) examined whether there are birth cohort changes in ability EI. The researchers theorised that because ability EI is an intelligence, it may be amenable to the Flynn effect, which refers to an observed rise in standardised intelligence test scores over time (Flynn, 1984). However, there was no evidence of changes in ability EI overall or for any of the underlying branches.

As there has already been a cross-temporal investigation of ability EI, this metaanalysis focuses on one of the EI models that uses self-report scales. Specifically, our focus is 
trait EI, as assessed with the Trait Emotional Intelligence Questionnaire (TEIQue). While there are several different theoretical models of EI, trait EI is the most theoretically comprehensive because it was based on a comprehensive synthesis of content drawn from all other major EI models (Petrides \& Furnham, 2001). That is, the 16 facets comprising trait EI were derived from: a) the four-branch ability model of Mayer, Caruso and Salovey (1999) (trait EI facets = perceiving emotions, expressing emotions, managing others' emotions, regulating one's own emotions were drawn); and b) models of social and emotional competence from both Bar-On (2000) and Goleman (1998) (trait EI facets = adaptability, assertiveness, low impulsivity, relationship skills, self-motivation, self-awareness, stressmanagement, self-esteem, empathy, happiness and optimism).

These 16 facets of trait EI are organised into four over-arching domains (wellbeing, self-control, emotionality and sociability) that underlie a single global EI super-factor. Wellbeing refers to a generalised sense of wellbeing that results from positive evaluations of the self, one's life and one's future (facets are self-esteem, happiness, and optimism). Selfcontrol refers to self-efficacy in regulating feelings and impulses (facets are emotion regulation, stress management, and low impulsiveness). Emotionality refers to accurate perceptions of one's own and others' feelings, effective expressions of feelings, and being able to use these qualities to enhance relationships (facets are emotion perception, emotion expression, relationship skills and empathy). Sociability is the self-perceived ability to influence others, communicate confidently and effectively network (facets are social competence, managing others' emotions, and assertiveness; Petrides, 2009). The Trait Emotional Intelligence Questionnaire-Short Form (Petrides, 2009) is a shortened, 30-item measure that is also based on the above domains. Similar to the full version, the TEIQue-SF demonstrates acceptable psychometric properties, such as meeting the minimum standard for 
reliability and demonstrating both criterion and incremental validity (e.g., Siegling, Saklofske, Vesely \& Nordstokke, 2012; Siegling, Vesely, Petrides, \& Saklofske, 2015).

Trait EI has been described as a personality construct comprised of emotion-related personality facets. While trait EI is distinct from major personality domains (i.e., it forms a separate distinct factor) it shows moderate to strong correlations with the big five broad personality domains (Petrides, Pita \& Kokkinaki, 2007; Perez-Gonzalez \& Sanchez-Ruiz, 2014). In fact, results from a large meta-analysis showed that trait EI (as measured by the TEIQue) is significantly associated with all five broad domains of personality, with the largest effect sizes for neuroticism $(\rho=-.68)$ and extraversion $(\rho=.56$; Van der Linden, Pekaar, Bakker, Schermer, Vernon, Dunkel \& Petrides, 2017). Different domains of trait EI show different levels of correlation with personality. In two large studies, neuroticism has very large negative correlations $(<-.70)$ with self-control and wellbeing, and extraversion has large positive correlations (around .50) with wellbeing and sociability (Siegling et al., 2015; Vernon, Villani, Schermer, \& Petrides, 2008).

The link between trait EI and broad domains of personality is relevant to our examination of cohort-level changes to trait EI because of known cohort changes to big five domains. Twenge's $(2000,2001)$ cross-temporal meta-analyses found an increase in both extraversion and neuroticism among American college students over a 40-year period. However, Smits, Dolan, Vorst, Wicherts, \& Timmerman (2011) found a slightly different result for generational change of personality among Europeans. They found a small increase in extraversion but a small decrease in neuroticism over a 25-year period ( $N=9,087$ Dutch university students). Given trait EI relates to higher extraversion and lower neuroticism, it is unclear whether trait EI would increase or decrease over generations in American samples, although trait EI may increase over generations in European samples. 
Beyond the big five domains of personality, another personality framework that relates to trait EI and may be used as a framework for predicting generational change in trait EI is Agency-Communion. The basis for Agency-Communion theory is that from an evolutionary perspective, people are interested in the pursuit of their own goals and in forming benevolent relationships with others. Agency is the dimension that relates to interests of the self, whereas communion is the dimension that relates to the interests of others (Bakan, 1966). Examples of agentic traits include being assertive, competitive, decisive and selfconfident and these traits are useful in the achievement of goals. Examples of communal traits include cooperation, expressivity, warmth, trustworthiness, interdependence and nurturance and these traits signify a focus on relationships.

The dyadic-interactional perspective on personality proposes that most personality traits on any level of the trait hierarchy comprise agentic or communal qualities (Wiggins \& Trapnell, 1996). According to this perspective, trait EI and its domains are likely to reflect agentic and/or communal concerns. Indeed, previous empirical evidence suggests that trait EI and its domains are characterised both by agency and communion (Siegling et al., 2012). Specifically, the trait EI domains wellbeing, sociability and self-control include facets such as optimism, self-esteem, emotion management, assertiveness that reflect agency. Conversely, the trait EI domain emotionality includes facets such as empathy that reflect communion. In accordance with this, agency was found to be a strong predictor of wellbeing, sociability and self-control whereas communion was a stronger predictor of emotionality. Based on cultural changes that have occurred in Western society (reviewed below) that have impacted agency and communion, we can explore possible reasons for generational change in trait EI.

\section{Cultural Changes in Western Society}

Western society has undergone a marked cultural transformation in recent decades, and this transformation is likely to impact levels of trait EI with time. A theoretical basis for 
why cultural changes may have influenced levels of trait EI over time arises from the mutual constitution model (Markus \& Kitayama, 2010). According to this model, the "self" is the individual's centre of experience - a constantly developing sense of awareness and agency, that forms as the individual (brain, body and psychological tendencies) adapts to the various environments it inhabits. One such environment is culture which is reflected in patterns of ideas, practices, institutions, products and artifacts (e.g., Adams \& Markus, 2004; Atran, Medin \& Ross, 2005; Shweder, 2003). More specifically, culture is reflected in the norms of its familial academic, religious, economic and political institutions (Markus \& Kitayama, 2010). Selves develop through the influence of the broader sociocultural environment and, in turn, individuals' thoughts, feelings and actions (i.e., the self) reinforce and change the sociocultural environment. This is the cycle of mutual constitution (Markus \& Kitayama, 2010), and as a consequence of this cycle, both the culture and the self are dynamic (Kashima, 2000; Kitayama, Duffy \& Uchida, 2007). Culture is dynamic because the ideas, practices, institutions, products and artifacts that comprise it are constantly changing with time. Selves, which comprise attitudes, values, beliefs and personalities, are dynamic because they change as their surrounding cultural contexts change. As such, the culture of different time periods is likely to produce generational differences in personality, similar to the way in which culture produces individual differences in personality between countries.

One way in which Western culture in countries such as the United States is changing with generations is through rising extrinsic individualism (e.g., Twenge, Campbell \& Freeman, 2012). The last few decades of Western society have been characterised by neoliberal governance which has transformed the cultural, political and economic landscape (Blyth \& Mark, 2002). Neoliberalism is a model of social studies and economics that emerged from principles of laissez-faire economic liberalism and free-market capitalism. The defining features of neoliberalism include economic liberalisation policies such as 
privatisation, austerity, deregulation, free-trade and reductions in government spending to increase the role of the private sector (Springer, Birch \& MacLeavy, 2016). These economic ideas and policies aim to foster unconstrained market-based competition and reward (Piketty, 2014). As a consequence of this competitive capitalist approach to governance in Western society, generations are evolving toward more extrinsic self-focus and rising individualism, characterised by increases in values such as materialism (e.g., Twenge et al., 2012).

Coinciding with these broad cultural changes, the previous decade witnessed a marked transformation of the digital landscape. Social media and personal smartphones have become pervasive in Western society. Due to its nature, social media has been implicated in facilitating the rise of individualism through its encouragement of self-display and fameseeking. Indeed, research has demonstrated that social media is directly tied to self-focused aspirations such as fame, image, money and status (Uhls, Zgourou \& Greenfield, 2014).

Apart from rising individualism, social media has been associated with mental health concerns. One reason is because social media such as Facebook and Instagram engender social comparison and peer envy, leading to depressive symptoms (Steers, Wickham \& Acitelli, 2014). A second reason is that individuals have begun to replace in-person interactions with social media (Twenge et al., 2018). In-person social interaction provides greater opportunity for emotional closeness and bonding compared to online communication, which is problematic if individuals are replacing in-person social interactions with online communication. A third reason is that time spent online on activities such as social media is associated with disrupted sleep because it delays sleep time but also because smartphones emit light that interrupt sleep-wake rhythms (Twenge, Krizan \& Hisler, 2017).

Overall, there have been documented increases in mood disorders, suicide ideation and suicide attempts since 2010 - a period that corresponds with the rise of social media and smartphones (Mojtabai, Olfson \& Han, 2016; Plemmons et al., 2018; Twenge et al., 2018). 
However, the rising cultural trends towards greater individualism have also resulted in generational increases in agentic traits (Twenge, 2006). The agentic traits that have increased in Western countries in samples diverse in socioeconomic status and education level include self-esteem, assertiveness, narcissism and high expectations (Gentile et al., 2010; Twenge, 2001; Twenge et al., 2008). Coinciding with increases in agency, there is some evidence for decreases in communal traits such as empathy (Konrath et al., 2011). Similarly, there have been changes in social capital; Putnam $(1995,2000)$ demonstrated that in the U.S. there have been declines in participation in voluntary civic organisations (e.g., bowling leagues, adult fraternal orders, the red cross, the boy scouts). Clearly, there have been many and varied cultural changes in the last two decades - however, based on the above, an a priori case may be made for trait EI and its domains either increasing or decreasing with time. For example, from one perspective, the rise in agentic traits may result in increases in the trait EI domain wellbeing, although the rise in mental health concerns may result in decreases in the same domain. The aim of the present study is to examine whether cultural changes in Western society have resulted in changes in trait EI and its domains - and, if so, in what direction. Accordingly, our research is exploratory.

\section{Assessing Generational Differences}

Assessing generational differences in personality traits can be achieved by examining birth cohorts, which are useful indicators of historical and cultural change (e.g., Caspi, 1987; Kertzer, 1983; Lambert, 1972; Stewart \& Healy, 1989). A birth cohort is typically defined as a group of people who are raised sharing a historical period (Kertzer, 1983). Birth cohort changes tend to occur in a relatively predictable way, coinciding with shifts in the larger sociocultural environment. The influence of the sociocultural environment is reflected in values and attitudes that develop during childhood and largely persist throughout life (Stewart \& Healy, 1989). 
When examined cross-sectionally, age effects are inherently confounded with birth cohort effects. Specifically, studies that compare different age groups are also comparing different cohorts; as such, it cannot be determined whether any differences are due to ageing or due to the effects of birth cohort. Whilst longitudinal designs are able to isolate the effects of the ageing process and eliminate birth cohort as a potential confound, the generalisability of the findings outside the cohort studied are limited, because age-graded development may differ between cohorts. For example, individuals born in the 1970s may have encountered different developmental changes compared to individuals born in the 1990s. Conversely, generational differences may be assessed using a cross-temporal meta-analysis; crosstemporal meta-analyses are a form of time-lag analysis, which is a method that examines similar aged-groups at different points in historical time (Schiae, 1965). As samples are of the same age, this method allows for the examination of birth cohort differences without the confound of age.

In terms of determining an appropriate time scale with which to conduct a crosstemporal meta-analysis, the rate of personality and behavioural change depends on the rate of cultural change that occurs in a given society. For example, technology has advanced so quickly that cultural change that has occurred as a result of the pervasiveness of digital communication is detected in periods much smaller than a full generation (e.g., Uhls \& Greenfield, 2011). This has also occurred in investigations of the impact of cultural change on child behaviour in China, arguably one of the most rapidly changing societies in the world (Zeng \& Greenfield, 2015). Accordingly, whilst one may argue that because EI is a relatively new concept not enough time has elapsed to detect generational differences in EI, this would not be the case if EI is indeed affected by relatively new changes in society such as social media.

\section{The Present Study}


In the present study, we aim to examine whether societal-level changes have coincided with changes in trait EI in young adults. We use a cross-temporal meta-analysis of Western university students' responses to the TEIQue. We focus solely on the TEIQue because other trait EI measures (e.g., the Bar-On EQ-i) have undergone multiple revisions, and thus are less amenable to the cross-temporal meta-analytic technique. We also control for two key demographic variables (gender composition of the sample, and the country where data was collected). This because there are known gender differences in trait EI scores (e.g., Petrides, 2009) and possible differences between Western countries in the extent of societal changes to individualism. To our knowledge, this is the first examination of generational differences in trait EI. This is theoretically important because: (1) the findings may provide evidence that the sociocultural environment is a predictor of the development of trait EI; (2) the findings will add to the body of literature of generational differences in individual difference variables.

\section{Method}

\section{Literature Search}

The first author conducted the literature search and coded the studies. First, Google Scholar, Sciverse Scopus, PsycInfo, Social Sciences Citation Index, Proquest Databases were searched for journal articles published prior to September 2019 that use the TEIQue. The following search terms were used: "Trait Emotional Intelligence Questionnaire," "TEIQue" and "TEIQue-SF." The process involved first searching and extracting relevant articles from Google Scholar. Because Google Scholar only returns the first 1000 results (and does not allow bulk export), the articles were searched and extracted separately for each year from 2001 to 2019. The other databases were then searched and any papers from the other databases that were not identified in Google Scholar were added. 
Second, papers that cited the test development articles for the TEIQue and the TEIQue-SF (Petrides, 2009; Petrides \& Furnham, 2001) were examined. Third, manual searches of journals that publish EI research were conducted. These included Personality and Individual Differences, Emotion, Journal of Personality Assessment, Journal of Personality and Journal of Research in Personality.

To avoid the file-drawer problem, ProQuest Dissertations and Google Scholar were searched for unpublished dissertations and conference papers. Authors of conference papers from Society for Personality and Social Psychology that met the inclusion criteria were also individually contacted. Following this, the reference lists of all included articles were inspected to identify additional articles. As a final step, authors of articles that met the inclusion criteria but did not report all of the required descriptive statistics were emailed (e.g., reported descriptive data for one subscale of the TEIQue, rather than all four).

\section{Inclusion Criteria}

To be included in the meta-analysis, studies needed to meet the following criteria: (1) mean or total score and standard deviation for at least one scale or subscale of the TEIQue;

(2) participants need to be undergraduates at conventional 4-year tertiary institutions (excluding for e.g., 2-year institutions or military academies), so that all participants are of a similar age; (3) participants need to be attending university in the United States, United Kingdom, Australia or Canada, as these are countries with similar cultural values (e.g., Hofstede, 1980; House, Hanges, Javidan, Dorfman \& Gupta, 2004); (4) the study involves an unselected group of participants as opposed to participants selected because they score high or low on a particular measure; (5) participants should not be clients at a counselling centre or diagnosed with any form of psychopathology; (6) participants' trait EI was assessed through self-report (not via the TEIQue-360, which uses observer-ratings of trait EI), as the nature of ratings may vary across types of measures. 
If studies involved experimental manipulations, pre-test means were used instead of post-test means. As this is a meta-analysis, we did not pre-determine sample size.

\section{Coding}

To code the year of data collection, the following procedure was used: if the year of data collected was reported in the study, this was coded directly; ii) if we obtained data directly from authors, they were asked to provide the year of data collection; iii) otherwise, year of data collection was coded as two years prior to publication of journal articles or one year prior to publication of grey literature (e.g., dissertations). This is a procedure that is commonly used in similar meta-analyses (e.g., Oliver \& Hyde, 1993; Twenge et al., 2008). The following variables were coded in order to control for their effects: (i) sex ratio i.e., percentage of women in the sample, as this is likely to influence EI means (e.g., Arteche, Chamorro-Premuzic, Furnham, \& Crump, 2008; Petrides, 2009; Siegling, Saklofske, Vesely, \& Nordstokke, 2012); (ii) country (U.S., U.K., Australia or Canada), using dummy coding, whereby Australia was the reference group. Most studies do not report information on the racial or socioeconomic status of their samples, so it was not possible to include these variables as controls. Some studies reported mean TEIQue and TEIQue-SF values, whilst others reported total scores; prior to analyses, we transformed total scores to mean scores so that each value was on the same (1 to 7) scale.

To provide more insight into our analyses, we also coded for two other country-level variables that vary over time, namely individualism and technology use (we thank the associate editor for this suggestion). We coded individualism for each country in our sample over time by obtaining raw data from waves 4-7 of World Values Survey (Inglehart et al., 2016); the World Values Survey began in 1981 and asks questions to individuals located in almost 100 countries regarding their values, attitudes, beliefs and wellbeing. One item asks about the importance they place on their friends in their life and another item asks about the 
importance of teaching a child independence. According to prior research on individualism, these two values are predictive of individualism (Hamamura, 2012). Accordingly, our proxy measure of individualism for each country combined the percentage of respondents who agreed with each value.

We obtained data regarding technology usage for each country over time using a dataset from Our World in Data (Ritchie, 2017). This data provides information on the percentage of individuals who have used the internet in a given country over each year. This proportion was used as a proxy for technology usage for each country over time.

\section{Data Analysis}

The cross-temporal meta-analysis technique is a modified meta-analysis technique that was developed across a series of studies by Twenge (e.g., Twenge, 2000; Twenge \& Campbell, 2001). In a cross-temporal meta-analysis, the method of data collection is identical to that used in a traditional meta-analysis. However, a traditional meta-analysis records the relevant effect size for each study whereas a cross-temporal meta-analysis records the sample means and year of data collection for each study. Using this information, meta-regression analyses was conducted, which allows each data point to be weighted by sample size and variability. In each analysis, year was entered as the predictor, and the respective trait EI scale was entered as the criterion.

Some cross-temporal meta-analyses calculate the magnitude of change in the relevant individual difference variable by using regression equations and the averaged standard deviation $(S D)$ of the individual samples. However, this approach does not take into account the differences in sample size. Instead, to calculate the magnitude of effects for time in standardized terms, we multiplied the unstandardised $\beta$ coefficients for time by 15 (which corresponds to the typical length of a social generation and the range of years for which data 
was available in our sample) and divided it by the relevant standard deviation of the TEIQue obtained from its technical manual (p.19, Petrides, 2009).

For more detail, the data is available at ( https://osf.io/wa54c/?view_only=d35256ed56f84038bbac6b22c59cbbde). This dataset contains other variables that were coded but not used in the analyses (e.g., type of article, region, measure). The data was analysed using Comprehensive Meta-analysis, Version 3.0, which does not use code. ${ }^{1}$

\section{Results}

Our dataset contained 70 studies with a combined sample size of 16,917 . Of those studies that reported the gender composition of the sample $(k=69, N=16,819)$, the range was $33 \%-100 \%$ female, with a mean of $67 \%$ female. Of those studies that reported the mean age of the sample $(k=58, N=14,254)$, the range was $17.78-29.00$, with a mean age of 20.96 years. Samples were from the U.S. (36\%), the U.K. (34\%), Canada (23\%) and Australia (6\%). $20 \%$ of studies used the TEIQue, whilst $80 \%$ of studies used the TEIQue-SF. Mean and standard deviation values for overall trait EI were reported in 61 studies. Mean and standard deviation values for at least one domain were reported in 29 studies. Across measures of the TEIQue, scores ranged from 1.77-5.31 $(M=4.81, S D=.68)$. Years of data collection ranged from 2003-2018. Due to missing data for some countries in some waves of the World Values Survey, individualism scores were only available for 32 of the studies.

To examine the effect of time (year of data collection) on trait EI and its domains, we conducted a series of meta-regression models controlling for gender composition and between-country differences. ${ }^{2}$ The results of these analyses, including effect sizes, $p$-values and $95 \%$ confidence intervals, are presented in Table 1 . When controlling for gender

\footnotetext{
${ }^{1}$ We did not pre-register this research in an independent, institutional registry

${ }^{2}$ We did not examine the effect of time on facets of trait EI because only one study out of 70 provided facet-level information.
} 
composition and between-country differences, time did not predict overall trait EI or sociability. However, when controlling for gender composition and between-gender differences, time significantly predicted wellbeing $(\beta=-.05 ; S E=.03 ; p<.05)$, self-control $(\beta=-.06 ; S E=.03 ; p<.05)$ and emotionality $(\beta=-.05 ; S E=.02 ; p<.05)$, whereby wellbeing, self-control and emotionality decreased with time. Figure 1 displays the relationships of wellbeing, self-control, and emotionality with time.

Insert Table 1 about here

Insert Figure 1 about here

In addition, we conducted meta-regression analyses examining the effect of time on trait EI and its domains by country. The results of these analyses, including effect sizes, pvalues and 95\% confidence intervals, are presented in Table 2 . When controlling for gender, time did not predict EI for either U.S. or U.K. samples. However, for Canadian samples, time significantly predicted overall trait EI $(\beta=-.03 ; S E=.01 ; p<.05)$, self-control $(\beta=-.06 ; S E$ $=.02 ; p<.001)$, emotionality $(\beta=-.05 ; S E=.01 ; p<.001)$ and sociability $(\beta=-.03 ; S E=$ $.01 ; p<.001)$, whereby overall trait EI, self-control, emotionality and sociability decreased with time. There were not enough studies to conduct analyses for Australian samples.

Insert Table 2 about here

\section{Curvilinear Analyses}

Beyond the main analyses, we investigated whether decreases in domains of trait EI were non-linear. This was to gain a more accurate understanding of the pattern of change that occurred over time. For ease of interpretability, we transformed time by subtracting the first year of data collection (i.e., 2003) from each year in our dataset, so that time ranged from 015 instead of 2003-2018. To test for possible non-linear effects, we introduced a squared term 
for our transformed variable of time in the meta-regression analyses. However, there was no evidence for non-linearity in any of the analyses. The output of these analyses is depicted in the supplementary information.

\section{Gender Composition and Time Interaction Effects}

We further investigated whether there were interaction effects between gender composition of the sample and time, to determine whether samples with greater proportions of a particular gender changed more in their EI scores over time. To perform these analyses, we centred variables for gender composition and time, to prevent issues with collinearity. Subsequently, we calculated an interaction term using the product of the centred variables for gender composition and time.

As demonstrated in Table 3, the interaction term was significant for wellbeing ( $\beta=$ $.47 ; S E=.16 ; p<.01)$ and self-control $(\beta=.41 ; S E=.17 ; p<.05)$. These findings indicate that declines in these domains of trait EI are stronger as the proportion of females in the sample decreases.

Insert Table 3 about here

\section{Individualism and Technology Analyses}

As discussed in the introduction, we speculated that changes in trait EI over time may be due to changes in individualism and technology usage. To more directly test these assumptions, we added indicators of individualism and technology usage to our metaregression analyses to determine whether these factors predict trait EI.

Our proxy for individualism significantly predicted wellbeing $(\beta=145.48 ; S E=$ 50.46; $p<.01)$ and self-control $(\beta=276.78 ; S E=61.10 ; p<.001)$, whereby individualism was associated with higher levels of wellbeing and self-control. Technology also significantly 
predicted wellbeing $(\beta=-7.89 ; S E=3.28 ; p<.05)$ and self-control $(\beta=-14.53 ; S E=3.98 ; p$ $<.001)$, whereby technology was associated with lower levels of wellbeing and self-control. The output of these analyses is illustrated in the supplementary information.

It is important to note that there were only a small number of studies (12 to 14 , depending on domain) for which both domain level EI scores and World Values Survey data were available. Consequently, the results of the individualism and technology analyses For EI domains should be treated cautiously.

\section{Discussion}

In the present study, trait EI measurements from 70 samples and 16,917 American, Canadian, British and Australian university students were meta-analysed to test for birth cohort differences between 2003 and 2018. When controlling for gender composition and between-country differences, overall trait EI, and the domain sociability did not change with time. However, wellbeing, self-control and emotionality displayed decreases with time. When conducting analyses by country, Canadian samples demonstrated decreases in overall trait EI, self-control, emotionality and sociability. Further analyses revealed that declines in wellbeing and self-control were stronger as the proportion of females in the samples decreased. Finally, individualism positively predicted wellbeing and self-control, whereas technology negatively predicted wellbeing and self-control. These findings will be considered in more detail below.

\section{Theoretical Implications}

There are a number of theoretical implications of the present findings. First, despite increases in agentic traits in Western society, wellbeing, self-control and emotionality demonstrated decreases with time. Within the trait EI framework, wellbeing comprises selfesteem, trait happiness and trait optimism, self-control comprises emotion regulation, stress management and impulsiveness (low) and emotionality comprises emotion expression, 
perception, relationship skills and empathy. Decreases in wellbeing, self-control and emotionality are consistent with the body of findings indicating rising levels of psychopathology (e.g., Mojtabai et al., 2016; Plemmons et al., 2018; Twenge et al., 2018). Specifically, these studies documented increases in mood disorders, suicide-related outcomes and deaths by suicide. Whilst the present study and these previous studies cannot establish causation, we can speculate as to why these findings are occurring. As mentioned, one possible reason is the rise of electronic communication, especially social media which has been linked to poor wellbeing (e.g., Augner \& Hacker, 2012; Huang, 2017; Shakya \& Christakis, 2017; Tromholt, 2016). The mechanisms behind which social media lead to poor wellbeing is that it replaces in-person communication resulting in increasing loneliness (Uhls et al., 2014), it facilitates social comparisons and peer envy (Steers et al., 2014) and disrupts sleep quality (Twenge et al., 2017). Besides social media, other possible factors that may explain declining wellbeing, self-control and emotionality include increasing academic pressure (Galloway, Connor \& Pope, 2013), greater family instability (Brown, Stykes \& Manning, 2016) and rising obesity levels (Hales et al., 2018). Specifically pinpointing the causes behind declining levels of wellbeing, self-control and emotionality is particularly important for prevention of mental health issues. Many antecedents of poor psychological wellbeing such as genetic predisposition, trauma and poverty are not amenable to intervention; if future research pinpoints the causes of poor psychological wellbeing that are indeed amenable to intervention then this may help prevent poor mental health outcomes in vulnerable populations.

An interesting side note regarding our finding for the trait EI domain of wellbeing is that it aligns with a general trend in well-being in our analysed countries over the given time period. Specifically, as part of supplementary analyses (recommended by an anonymous reviewer) using happiness scale scores from the World Values Survey, we observed a 
significant decrease in happiness scores over the past two decades in a sample comprising the US, UK, Canada, and Australia. The similar trend raises questions about the extent to which well-being as assessed in the trait EI domain is synonymous with more general conceptualisations of well-being. This is relevant because well-being is often considered an outcome of trait EI rather than a component of it (e.g., Di Fabio \& Kenny, 2016). If this view is accepted, then this has implications for the causal sequencing of the effects among the trait EI domains. Specifically, it is possible that wellbeing may have declined over time as a consequence of declines in other facets of trait EI (e.g., self-control and emotionality). Future research should aim to pinpoint the causal sequences implicated in declines in trait EI domains over time.

Another implication of the present findings is that they provide some evidence that the sociocultural environment is a predictor of trait EI. Much of the extant literature on EI has focused on the various beneficial outcomes of EI such as improved mental health, physical health, relationship quality and job performance (Joseph \& Newman, 2010; Mikolajczak et al., 2008; Mikolajczak et al., 2007). Whilst this is undoubtedly a theoretically and practically important stream of research, it is important to consider the predictors of EI, rather than just the outcomes. We theorised that the sociocultural environment would be a predictor of trait EI based on the mutual constitution model (Markus \& Kitayama, 2010). This model asserts that selves, comprising values, beliefs and personalities change as the broader cultural context changes. Indeed, by including indices of individualism and technology in our metaregression analyses, we were able to pinpoint aspects of the sociocultural environment that seem responsible in changes in trait EI. Specifically, our finding that technology usage predicted decreases in the trait EI domains of wellbeing and self-control is consistent with the body of literature pinpointing rising electronic communication with psychopathology (Augner \& Hacker, 2012; Huang, 2017; Shakya \& Christakis, 2017; Tromholt, 2016). 
However, it is important to note that whilst we theorised that rising levels of individualism may lead to declines in trait EI, our results were contrary to this prediction. This may be because our proxy measure of individualism solely consisted of indexing the extent to which individuals considered the importance of friends and teaching a child independence (Hamamura, 2012). Whilst these may be aspects of individualism that are conducive to increases in trait EI, there may be other aspects of individualism that are responsible for decreases in trait EI. Additionally, as noted above, the small number of studies on which these findings were based suggests caution in interpreting these findings definitively.

Our findings are also intriguing in light of the cross-temporal meta-analysis conducted by Pietschnig and Gittler (2017), which demonstrated that there were no changes in ability EI over time at either the overall or subscale level. Unlike our theoretical arguments regarding why trait EI may change with time, Pietschnig and Gittler (2017) hypothesised that because ability EI constitutes an intelligence, it may be amenable to the Flynn effect. Researchers have attributed to the Flynn effect to factors such as decreased sibship sizes (Sundet, Borren \& Tambs, 2008), improvements in pre- and post-natal nutrition (Lynn, 2009) and improvements in child rearing (Elley, 1969). Pietschnig and Gittler (2017) speculated that perhaps ability EI did not change with time because the causes of the Flynn effect are not applicable to ability EI. Another explanation relates to the construct validity of ability EI perhaps ability EI may partially reflect personality, in which case the Flynn effect would be difficult to detect. However, this explanation is unlikely because numerous studies have provided empirical evidence that ability EI is indeed located within the structure of human cognitive abilities (MacCann, Joseph, Newman \& Roberts, 2014). Ultimately, the findings of our cross-temporal meta-analysis in conjunction with the findings of Pietschnig and Gittler (2017) paint a bleak picture of society's EI - whilst ability EI scores remain unchanged, domains of trait EI are declining over time. 


\section{Practical Implications}

Several systematic reviews and meta-analyses provide convincing evidence that EI interventions succeed in raising individuals' level of EI, even in the long-term (Hodzic, Scharfen, Ripoll, Holling \& Zenasni, 2018; Kotsou, Mikolajczak, Heeren, Grégoire \& Leys, 2019; Schutte, Malouff \& Thorsteinsson, 2013). More relevantly, EI interventions that used the trait EI framework were successful in improving trait EI in university students (Nelis, Quoidbach, Mikolajczak \& Hansenne, 2009; Nelis et al., 2011). Beyond improving trait EI, these interventions were also successful in improving participants' social relationships and employability. As our findings demonstrate declines in domains of trait EI, there is a need for interventions among this population which may help mitigate the decline. In addition, therapists, particularly those working among university populations, should be aware of changing societal trends and the potential reasons underlying these changes.

\section{Limitations and Future Research}

Despite the strengths of the present study, limitations should be noted. As with any meta-analysis, our results are only as strong as the original studies included in the metaanalysis. Given that many of the original studies in our meta-analysis did not report potentially relevant variables such as the ethnic composition of the sample, we were unable to determine whether ethnicity moderated our findings. Second, although the majority of studies included in our meta-analysis reported mean trait EI scores, fewer studies reported mean subscale scores $(k=26-29 ; N=7,695-8,250)$. Accordingly, our meta-analysis may have lacked power to detect significant effects for sociability which demonstrated trends toward significance $(p<.10)$.

Apart from the future research directions mentioned above, another avenue for future research is to determine the extent to which our findings generalise to other EI measures. Whilst there are no changes in ability EI with time (see Pietschnig \& Gittler, 2017), it may be 
useful to examine whether changes are observed in other self-report EI measures such as the Bar-On EQ-i. However, the Bar-On EQ-i was revised in 2011, so it is likely that enough time has not elapsed to detect changes across birth cohorts.

In conclusion, Western society witnessed enormous cultural changes in the last two decades brought about by rising individualism and the advent of social media. Our study found that whilst overall trait EI did not change with time, the domains wellbeing, selfcontrol and emotionality demonstrated significant decreases with time. These findings complement existing literature indicating increasing extrinsic individualism, narcissism and rising psychopathology. We hope our paper stimulates further research into investigating the causes of these alarming societal trends. 


\section{References}

Adams, G., \& Markus, H. R. (2004). Toward a conception of culture suitable for a social psychology of culture. The psychological foundations of culture, 335-360.

Anderson, M., \& Jiang, J. (2018). Teens, social media \& technology 2018. Pew Research Center, 31, 2018.

Arteche, A., Chamorro-Premuzic, T., Furnham, A., \& Crump, J. (2008). The relationship of trait EI with personality, IQ and sex in a UK sample of employees. International Journal of Selection and Assessment, 16(4), 421-426.

Ashkanasy, N. M., \& Daus, C. S. (2005). Rumors of the death of emotional intelligence in organizational behavior are vastly exaggerated. Journal of Organizational Behavior, 26(4), 441-452.

Atran, S., Medin, D. L., \& Ross, N. O. (2005). The cultural mind: environmental decision making and cultural modeling within and across populations. Psychological Review, 112(4), 744.

Augner, C., \& Hacker, G. W. (2012). Associations between problematic mobile phone use and psychological parameters in young adults. International Journal of Public Health, 57(2), 437-441.

Bakan, D. (1966). The duality of human existence: Isolation and communion in western man. Boston: Beacon Press.

Bar-On, R. (1997). BarOn emotional quotient inventory. Multi-Health Systems.

Bar-On, R. (2000). Emotional and social intelligence: Insights from the Emotional Quotient Inventory. In R. Bar-On \& J. D. A. Parker (Eds.) The handbook of emotional intelligence: Theory, development, assessment, and application at home, school, and in the workplace (pp. 363-388). San Francisco, CA: Jossey-Bass. 
Baumeister, R. F., \& Leary, M. R. (1995). The need to belong: desire for interpersonal attachments as a fundamental human motivation. Psychological Bulletin, 117(3), 497. Blyth, M., \& Mark, B. (2002). Great transformations: Economic ideas and institutional change in the twentieth century. Cambridge University Press.

Booth, R. W., Sharma, D., \& Leader, T. I. (2016). The age of anxiety? It depends where you look: changes in STAI trait anxiety, 1970-2010. Social Psychiatry and Psychiatric Epidemiology, 51(2), 193-202.

Brackett, M. A., Rivers, S. E., Shiffman, S., Lerner, N., \& Salovey, P. (2006). Relating emotional abilities to social functioning: a comparison of self-report and performance measures of emotional intelligence. Journal of Personality and Social Psychology, 91(4), 780.

Brown, S. L., Stykes, J. B., \& Manning, W. D. (2016). Trends in children's family instability, 1995-2010. Journal of Marriage and Family, 78(5), 1173-1183.

Caspi, A. (1987). Personality in the life course. Journal of Personality and Social Psychology, 53(6), 1203.

Dunkel, C. S., \& Van der Linden, D. (2014). Evidence for the general factor of personality as social-effectiveness. Personality and Individual Differences, 64, 147-151.

Elley, W. B. (1969). Changes in mental ability in New Zealand. New Zealand Journal of Educational Studies, 4, 140-155.

Galloway, M., Conner, J., \& Pope, D. (2013). Nonacademic effects of homework in privileged, high-performing high schools. The Journal of Experimental Education, 81(4), 490-510.

Gentile, B., Twenge, J. M., \& Campbell, W. K. (2010). Birth cohort differences in selfesteem, 1988-2008: A cross-temporal meta-analysis. Review of General Psychology, 14(3), 261-268. 
Goleman, D. (1998). Working with emotional intelligence. London, UK: Bloomsbury.

Hales, C. M., Fryar, C. D., Carroll, M. D., Freedman, D. S., \& Ogden, C. L. (2018). Trends in obesity and severe obesity prevalence in US youth and adults by sex and age, 20072008 to 2015-2016. Jama, 319(16), 1723-1725.

Hedges, L. V., \& Becker, B. J. (1986). Statistical methods in the meta-analysis of research on gender differences. In The Psychology of Gender: Progress Through Meta-Analysis. The Johns Hopkins University Press.

Hodzic, S., Scharfen, J., Ripoll, P., Holling, H., \& Zenasni, F. (2018). How efficient are emotional intelligence trainings: a meta-analysis. Emotion Review, 10(2), 138-148.

Huang, C. (2017). Time spent on social network sites and psychological well-being: A metaanalysis. Cyberpsychology, Behavior, and Social Networking, 20(6), 346-354.

Inglehart, R., Haerpfer, C., Moreno, A., Welzel, C., Kizilova, K., Diez-Medrano, J., Lagos, M., Norris, P., Ponarin, E., \& Puranen, B et al. (eds). (2016). World Values Survey: All Rounds - Country-Pooled Datafile Version:

\section{https://www.worldvaluessurvey.org/WVSDocumentationWVL.jsp. Madrid: JD}

Systems Institute.

Joseph, D. L., \& Newman, D. A. (2010). Emotional intelligence: an integrative meta-analysis and cascading model. Journal of Applied Psychology, 95(1), 54.

Lambert, W. E. (1972). Language, psychology, and culture.

Loehlin, J. C., \& Nichols, R. C. (2012). Heredity, environment, and personality: A study of 850 sets of twins. University of Texas Press.

Kashima, Y. (2000). Maintaining cultural stereotypes in the serial reproduction of narratives. Personality and Social Psychology Bulletin, 26(5), 594-604.

Kertzer, D. I. (1983). Generation as a sociological problem. Annual Review of Sociology, 9(1), 125-149. 
Kitayama, S., Duffy, S., \& Uchida, Y. (2007). Self as cultural mode of being. Handbook of Cultural Psychology, 136-174.

Konrath, S. H., O'Brien, E. H., \& Hsing, C. (2011). Changes in dispositional empathy in American college students over time: A meta-analysis. Personality and Social Psychology Review, 15(2), 180-198.

Kotsou, I., Mikolajczak, M., Heeren, A., Grégoire, J., \& Leys, C. (2019). Improving emotional intelligence: a systematic review of existing work and future challenges. Emotion Review, 11(2), 151-165.

MacCann, C., Joseph, D. L., Newman, D. A., \& Roberts, R. D. (2014). Emotional intelligence is a second-stratum factor of intelligence: Evidence from hierarchical and bifactor models. Emotion, 14(2), 358.

Markus, H. R., \& Kitayama, S. (2010). Cultures and selves: A cycle of mutual constitution. Perspectives on Psychological Science, 5(4), 420-430.

Mayer, J. D., Caruso, D. R., \& Salovey, P. (1999). Emotional intelligence meets traditional standards for an intelligence. Intelligence, 27(4), 267-298.

Mikolajczak, M., Nelis, D., Hansenne, M., \& Quoidbach, J. (2008). If you can regulate sadness, you can probably regulate shame: Associations between trait emotional intelligence, emotion regulation and coping efficiency across discrete emotions. Personality and Individual Differences, 44(6), 1356-1368.

Mikolajczak, M., Roy, E., Luminet, O., Fillée, C., \& De Timary, P. (2007). The moderating impact of emotional intelligence on free cortisol responses to stress. Psychoneuroendocrinology, 32(8-10), 1000-1012.

Mojtabai, R., Olfson, M., \& Han, B. (2016). National trends in the prevalence and treatment of depression in adolescents and young adults. Pediatrics, 138(6), e20161878. 
Musek, J. (2007). A general factor of personality: Evidence for the Big One in the five-factor model. Journal of Research in Personality, 41(6), 1213-1233.

Nelis, D., Kotsou, I., Quoidbach, J., Hansenne, M., Weytens, F., Dupuis, P., \& Mikolajczak, M. (2011). Increasing emotional competence improves psychological and physical well-being, social relationships, and employability. Emotion, 11(2), 354.

Nelis, D., Quoidbach, J., Mikolajczak, M., \& Hansenne, M. (2009). Increasing emotional intelligence:(How) is it possible?. Personality and Individual Differences, 47(1), 3641.

Oliver, M. B., \& Hyde, J. S. (1993). Gender differences in sexuality: a metaanalysis. Psychological Bulletin, 114(1), 29.

Petrides, K. V. (2009). Psychometric properties of the trait emotional intelligence questionnaire (TEIQue). In Assessing emotional intelligence (pp. 85-101). Springer, Boston, MA.

Petrides, K. V., \& Furnham, A. (2001). Trait emotional intelligence: Psychometric investigation with reference to established trait taxonomies. European Journal of Personality, 15(6), 425-448.

Petrides, K. V., Pita, R., \& Kokkinaki, F. (2007). The location of trait emotional intelligence in personality factor space. British Journal of Psychology, 98(2), 273-289.

Petrides, K.V. (2009). Technical manual for the Trait Emotional Intelligence Questionnaire (TEIQue) $\left(1^{\text {st }}\right.$ edition, $4^{\text {th }}$ printing). London: London Psychometric Laboratory.

Pietschnig, J., \& Gittler, G. (2017). Is ability-based emotional intelligence impervious to the Flynn effect? A cross-temporal meta-analysis (2001-2015). Intelligence, 61, 37-45.

Plemmons, G., Hall, M., Doupnik, S., Gay, J., Brown, C., Browning, W., ... \& Rehm, K. (2018). Hospitalization for suicide ideation or attempt: 20082015. Pediatrics, 141(6), e20172426. 
Putnam, R. D. (1995). Tuning in, tuning out: The strange disappearance of social capital in America. PS: Political Science \& Politics, 28(4), 664-683.

Putnam, R. D. (2000). Bowling alone: America's declining social capital. In Culture and politics (pp. 223-234). Palgrave Macmillan, New York.

Ritchie, H. (2017). “Technology Adoption.” Published online at Our WorldInData.Org. Retrieved from: ‘https://ourworldindata.org/technology-adoption' [Online Resource]

Rosnow, R. L., Rosenthal, R., \& Rubin, D. B. (2000). Contrasts and correlations in effectsize estimation. Psychological Science, 11(6), 446-453.

Rushton, J. P., Bons, T. A., \& Hur, Y. M. (2008). The genetics and evolution of the general factor of personality. Journal of Research in Personality, 42(5), 1173-1185.

Schaie, K. W. (1965). A general model for the study of developmental problems. Psychological Bulletin, 64(2), 92.

Schutte, N. S., Malouff, J. M., \& Thorsteinsson, E. B. (2013). Increasing emotional intelligence through training: Current status and future directions. International Journal of Emotional Education, 5(1), 56.

Shakya, H. B., \& Christakis, N. A. (2017). Association of Facebook use with compromised well-being: A longitudinal study. American Journal of Epidemiology, 185(3), 203211.

Shweder, R. A. (2003). Why do men barbecue?: Recipes for cultural psychology. Harvard University Press.

Siegling, A. B., Saklofske, D. H., Vesely, A. K., \& Nordstokke, D. W. (2012). Relations of emotional intelligence with gender-linked personality: Implications for a refinement of EI constructs. Personality and Individual Differences, 52(7), 776-781. 
Siegling, A. B., Vesely, A. K., Petrides, K. V., \& Saklofske, D. H. (2015). Incremental validity of the trait emotional intelligence questionnaire-short form (TEIQueSF). Journal of Personality Assessment, 97(5), 525-535.

Smith, A., \& Anderson, M. (2018). Social media use in 2018. Pew Research Center, 1.

Springer, S., Birch, K., \& MacLeavy, J. (Eds.). (2016). Handbook of neoliberalism. Routledge.

Steers, M. L. N., Wickham, R. E., \& Acitelli, L. K. (2014). Seeing everyone else's highlight reels: How Facebook usage is linked to depressive symptoms. Journal of Social and Clinical Psychology, 33(8), 701-731.

Stewart, A. J., \& Healy, J. M. (1989). Linking individual development and social changes. American Psychologist, 44(1), 30.

Sundet, J. M., Borren, I., \& Tambs, K. (2008). The Flynn effect is partly caused by changing fertility patterns. Intelligence, 36(3), 183-191.

Tromholt, M. (2016). The Facebook experiment: Quitting Facebook leads to higher levels of well-being. Cyberpsychology, behavior, and social networking, 19(11), 661-666.

Twenge, J. M. (2001). Changes in women's assertiveness in response to status and roles: A cross-temporal meta-analysis, 1931-1993. Journal of Personality and Social Psychology, 81(1), 133.

Twenge, J. M., \& Campbell, W. K. (2001). Age and birth cohort differences in self-esteem: A cross-temporal meta-analysis. Personality and Social Psychology Review, 5(4), 321344.

Twenge, J. M., Campbell, W. K., \& Freeman, E. C. (2012). Generational differences in young adults' life goals, concern for others, and civic orientation, 1966-2009. Journal of Personality and Social Psychology, 102(5), 1045. 
Twenge, J. M., Gentile, B., DeWall, C. N., Ma, D., Lacefield, K., \& Schurtz, D. R. (2010). Birth cohort increases in psychopathology among young Americans, 1938-2007: A cross-temporal meta-analysis of the MMPI. Clinical Psychology Review, 30(2), 145 154.

Twenge, J. M., Konrath, S., Foster, J. D., Keith Campbell, W., \& Bushman, B. J. (2008). Egos inflating over time: A cross-temporal meta-analysis of the Narcissistic Personality Inventory. Journal of Personality, 76(4), 875-902.

Twenge, J. M., Krizan, Z., \& Hisler, G. (2017). Decreases in self-reported sleep duration among US adolescents 2009-2015 and association with new media screen time. Sleep Medicine, 39, 47-53.

Twenge, J. M., Joiner, T. E., Rogers, M. L., \& Martin, G. N. (2018). Increases in depressive symptoms, suicide-related outcomes, and suicide rates among US adolescents after 2010 and links to increased new media screen time. Clinical Psychological Science, 6(1), 3-17.

Uhls, Y. T., \& Greenfield, P. M. (2011). The rise of fame: An historical content analysis. Cyberpsychology: Journal of Psychosocial Research on Cyberspace, 5(1).

Uhls, Y. T., Zgourou, E., \& Greenfield, P. M. (2014). 21st century media, fame, and other future aspirations: A national survey of 9-15 year olds. Cyberpsychology: Journal of Psychosocial Research on Cyberspace, 8(4).

van der Linden, D., Pekaar, K. A., Bakker, A. B., Schermer, J. A., Vernon, P. A., Dunkel, C. S., \& Petrides, K. V. (2017). Overlap between the general factor of personality and emotional intelligence: A meta-analysis. Psychological Bulletin, 143(1), 36.

Vernon, P. A., Villani, V. C., Schermer, J. A., \& Petrides, K. V. (2008). Phenotypic and genetic associations between the Big Five and trait emotional intelligence. Twin Research and Human Genetics, 11(5), 524-530. 
Wiggins, J. S., \& Trapnell, P. D. (1996). A dyadic-interactional perspective on the five-factor model. In J. S. Wiggins (Ed.), The fivefactor model of personality: Theoretical perspectives (pp. 88-162). New York: Guilford Press.

Zeng, R., \& Greenfield, P. M. (2015). Cultural evolution over the last 40 years in China: Using the Google Ngram Viewer to study implications of social and political change for cultural values. International Journal of Psychology, 50(1), 47-55. 
Table 1

Meta-regression Analyses examining the Effect of Time on Trait EI controlling for Gender

Composition and Country

\begin{tabular}{|c|c|c|c|c|c|c|c|c|}
\hline & $\boldsymbol{k}$ & $\boldsymbol{\beta}$ & $S E$ & $95 \% L$ & $95 \% U$ & $Z$ & p-value & $\begin{array}{c}\text { Standardised } \\
\text { Effect size }\end{array}$ \\
\hline $\begin{array}{c}\text { Overall Trait } \\
\text { EI }\end{array}$ & 59 & & & & & & & \\
\hline Intercept & & 5.28 & 1.07 & 3.19 & 7.37 & 4.94 & $<.001 * * *$ & \\
\hline Gender & & -0.67 & 0.91 & -2.44 & 1.11 & -0.73 & 0.46 & \\
\hline $\begin{array}{l}\text { Composition } \\
\text { Country } \\
\text { (reference } \\
\text { group = } \\
\text { Australia) }\end{array}$ & & & & & & & & \\
\hline $\begin{array}{l}\text { USA vs } \\
\text { Australia }\end{array}$ & & 0.32 & 0.67 & -1.05 & 1.63 & 0.43 & 0.67 & \\
\hline $\begin{array}{l}\text { Canada vs } \\
\text { Australia }\end{array}$ & & 0.29 & 0.68 & -1.05 & 1.63 & 0.43 & 0.67 & \\
\hline $\begin{array}{l}\text { UK vs } \\
\text { Australia }\end{array}$ & & -0.09 & 0.70 & -1.47 & 1.29 & -0.12 & 0.90 & \\
\hline $\begin{array}{l}\text { Time } \\
\text { Wellbeing }\end{array}$ & 26 & -0.02 & 0.05 & -0.12 & 0.08 & -0.40 & 0.69 & -0.51 \\
\hline Intercept & & 6.30 & 0.55 & 5.22 & 7.38 & 11.42 & $<.001 * * *$ & \\
\hline $\begin{array}{l}\text { Gender } \\
\text { Composition }\end{array}$ & & -0.58 & 0.53 & -1.63 & 0.46 & -1.10 & 0.27 & \\
\hline $\begin{array}{l}\text { USA vs } \\
\text { Australia }\end{array}$ & & -0.03 & 0.39 & -0.80 & 0.74 & -0.07 & 0.94 & \\
\hline $\begin{array}{l}\text { Canada vs } \\
\text { Australia }\end{array}$ & & 0.02 & 0.39 & -0.75 & 0.79 & 0.05 & 0.96 & \\
\hline $\begin{array}{l}\text { UK vs } \\
\text { Australia }\end{array}$ & & -0.53 & 0.40 & -1.31 & 0.26 & -1.32 & 0.18 & \\
\hline $\begin{array}{l}\text { Time } \\
\text { Self-Control }\end{array}$ & 26 & -0.05 & 0.03 & -0.10 & -0.01 & -2.18 & $<.05^{*}$ & -0.90 \\
\hline Intercept & & 5.11 & 0.58 & 3.97 & 6.26 & 8.78 & $<.001 * * *$ & \\
\hline $\begin{array}{l}\text { Gender } \\
\text { Composition }\end{array}$ & & -0.14 & 0.56 & -1.25 & 0.96 & -0.26 & 0.80 & \\
\hline $\begin{array}{l}\text { USA vs } \\
\text { Australia }\end{array}$ & & 0.03 & 0.41 & -0.77 & 0.84 & 0.08 & 0.93 & \\
\hline $\begin{array}{l}\text { Canada vs } \\
\text { Australia }\end{array}$ & & 0.01 & 0.41 & -0.80 & 0.82 & 0.03 & 0.98 & \\
\hline $\begin{array}{l}\text { UK vs } \\
\text { Australia }\end{array}$ & & -0.40 & 0.42 & -1.22 & 0.43 & -0.95 & 0.34 & \\
\hline $\begin{array}{l}\text { Time } \\
\text { Emotionality }\end{array}$ & 29 & -0.06 & 0.03 & -0.11 & -0.01 & -2.33 & $<.05^{*}$ & -1.13 \\
\hline Intercept & & 5.36 & 0.48 & 4.42 & 6.29 & 11.22 & $<.001 * * *$ & \\
\hline $\begin{array}{l}\text { Gender } \\
\text { Composition }\end{array}$ & & -0.15 & 0.46 & -0.76 & 1.05 & 0.32 & 0.74 & \\
\hline
\end{tabular}




\begin{tabular}{|c|c|c|c|c|c|c|c|c|}
\hline \multicolumn{2}{|l|}{$\begin{array}{l}\text { USA vs } \\
\text { Australia }\end{array}$} & -0.10 & 0.34 & -0.76 & 0.56 & -0.29 & 0.77 & \\
\hline $\begin{array}{l}\text { Canada vs } \\
\text { Australia }\end{array}$ & & -0.02 & 0.34 & -0.69 & 0.64 & -0.07 & 0.95 & \\
\hline $\begin{array}{l}\text { UK vs } \\
\text { Australia }\end{array}$ & & -0.23 & 0.35 & -0.90 & 0.45 & -0.65 & 0.52 & \\
\hline $\begin{array}{l}\text { Time } \\
\text { Sociability }\end{array}$ & 26 & -0.05 & 0.02 & -0.09 & -0.01 & -2.22 & $<0.05$ & -1.06 \\
\hline Intercept & & 5.58 & 0.37 & 4.85 & 6.31 & 14.98 & $<.001 * * *$ & \\
\hline $\begin{array}{l}\text { Gender } \\
\text { Composition }\end{array}$ & & -0.64 & 0.36 & -1.35 & 0.07 & -1.77 & 0.08 & \\
\hline $\begin{array}{l}\text { USA vs } \\
\text { Australia }\end{array}$ & & 0.04 & 0.26 & -0.55 & 0.47 & -0.17 & 0.87 & \\
\hline $\begin{array}{l}\text { Canada vs } \\
\text { Australia }\end{array}$ & & 0.02 & 0.26 & -0.49 & 0.53 & 0.08 & 0.94 & \\
\hline $\begin{array}{l}\text { UK vs } \\
\text { Australia }\end{array}$ & & -0.21 & 0.27 & -0.73 & 0.31 & -0.78 & 0.44 & \\
\hline Time & & -0.03 & 0.02 & -0.06 & 0.00 & -1.85 & 0.07 & -0.60 \\
\hline
\end{tabular}


Table 2

Meta-regression Analyses examining the Effect of Time on Trait EI by Country

\begin{tabular}{|c|c|c|c|c|c|c|c|c|}
\hline & $\boldsymbol{k}$ & $\beta$ & $S E$ & $95 \% L$ & $95 \% U$ & $Z$ & p-value & $\begin{array}{l}\text { Standardised } \\
\text { Effect size }\end{array}$ \\
\hline $\begin{array}{c}\text { U.S. } \\
\text { Overall Trait } \\
\text { EI }\end{array}$ & 22 & & & & & & & \\
\hline Intercept & & 5.42 & 0.41 & 4.60 & 6.23 & 13.08 & $<.001 * * *$ & \\
\hline $\begin{array}{l}\text { Gender } \\
\text { Composition }\end{array}$ & & -0.53 & 0.53 & -1.56 & 0.50 & -1.01 & 0.31 & \\
\hline $\begin{array}{l}\text { Time } \\
\text { Wellbeing }\end{array}$ & 10 & -0.01 & 0.03 & -0.08 & 0.06 & -0.32 & 0.75 & -0.25 \\
\hline $\begin{array}{l}\text { Intercept } \\
\text { Gender }\end{array}$ & & $\begin{array}{c}6.38 \\
-1.17\end{array}$ & $\begin{array}{l}0.68 \\
0.93\end{array}$ & $\begin{array}{c}5.04 \\
-2.98\end{array}$ & $\begin{array}{l}7.72 \\
0.64\end{array}$ & $\begin{array}{c}9.36 \\
-1.27\end{array}$ & $\begin{array}{c}<.001^{* *} \\
0.21\end{array}$ & \\
\hline Composition & & & & & & & & \\
\hline $\begin{array}{l}\text { Time } \\
\text { Self-Control }\end{array}$ & 10 & -0.03 & 0.05 & -0.13 & 0.08 & -0.54 & 0.59 & -0.54 \\
\hline $\begin{array}{l}\text { Intercept } \\
\text { Gender }\end{array}$ & & $\begin{array}{c}4.91 \\
-0.47\end{array}$ & $\begin{array}{l}0.72 \\
0.97\end{array}$ & $\begin{array}{l}3.50 \\
-2.37\end{array}$ & $\begin{array}{l}6.32 \\
1.44\end{array}$ & $\begin{array}{c}6.84 \\
-0.48\end{array}$ & $\begin{array}{c}<.001 * * \\
0.63\end{array}$ & \\
\hline Composition & & & & & & & & \\
\hline $\begin{array}{l}\text { Time } \\
\text { Emotionality }\end{array}$ & 11 & -0.02 & 0.06 & -0.13 & 0.09 & -0.29 & 0.78 & -0.38 \\
\hline Intercept & & 5.39 & 0.71 & 3.99 & 6.79 & 7.56 & $<.001 * * *$ & \\
\hline $\begin{array}{l}\text { Gender } \\
\text { Composition }\end{array}$ & & -0.34 & 0.98 & -2.26 & 1.59 & -0.34 & 0.73 & \\
\hline $\begin{array}{l}\text { Time } \\
\text { Sociability }\end{array}$ & 9 & -0.03 & 0.06 & -0.15 & 0.09 & -0.51 & 0.61 & -0.63 \\
\hline Intercept & & 5.73 & 0.70 & 4.36 & 7.11 & 8.16 & $<.001 * *$ & \\
\hline $\begin{array}{l}\text { Gender } \\
\text { Composition }\end{array}$ & & -0.88 & 0.95 & -2.74 & 0.99 & -0.92 & 0.36 & \\
\hline $\begin{array}{l}\text { Time } \\
\text { U.K. }\end{array}$ & & -0.04 & 0.06 & -0.15 & 0.08 & -0.62 & 0.53 & -0.80 \\
\hline $\begin{array}{c}\text { Overall Trait } \\
\text { EI }\end{array}$ & 20 & & & & & & & \\
\hline Intercept & & 5.78 & 2.41 & 1.05 & 10.51 & 2.39 & 0.02 & \\
\hline $\begin{array}{l}\text { Gender } \\
\text { Composition }\end{array}$ & & -1.43 & 2.89 & -7.10 & 4.24 & -0.49 & 0.62 & \\
\hline $\begin{array}{l}\text { Time } \\
\text { Wellbeing }\end{array}$ & 7 & -0.04 & 0.13 & -0.29 & 0.22 & -0.27 & 0.78 & -1.02 \\
\hline Intercept & & 5.82 & 0.89 & 4.07 & 7.54 & 6.56 & $<.001 * * *$ & \\
\hline $\begin{array}{l}\text { Gender } \\
\text { Composition }\end{array}$ & & -0.45 & 1.27 & -2.95 & 2.05 & -0.35 & 0.72 & \\
\hline $\begin{array}{l}\text { Time } \\
\text { Self-Control }\end{array}$ & 7 & -0.07 & 0.06 & -0.17 & 0.04 & -1.21 & 0.22 & -1.27 \\
\hline Intercept & & 4.97 & 0.93 & 3.14 & 6.78 & 5.36 & $<.001 * * *$ & \\
\hline $\begin{array}{l}\text { Gender } \\
\text { Composition }\end{array}$ & & -0.21 & 1.33 & -2.81 & 2.40 & -0.16 & 0.88 & \\
\hline Time & & -0.08 & 0.06 & -0.20 & 0.03 & -1.47 & 0.14 & -1.52 \\
\hline
\end{tabular}




\begin{tabular}{|c|c|c|c|c|c|c|c|c|}
\hline Emotionality & 7 & & & & & & & \\
\hline Intercept & & 4.98 & 0.66 & 3.68 & 6.28 & 7.52 & $<.001 * * *$ & \\
\hline Gender & & 0.47 & 0.95 & -1.39 & 2.33 & 0.50 & 0.62 & \\
\hline \multicolumn{9}{|l|}{ Composition } \\
\hline $\begin{array}{l}\text { Time } \\
\text { Sociability }\end{array}$ & 7 & -0.05 & 0.04 & -0.13 & 0.03 & -1.26 & 0.21 & -1.06 \\
\hline Intercept & & 5.13 & 0.33 & 4.48 & 5.77 & 15.62 & $<.001 * * *$ & \\
\hline Gender & & -0.42 & 0.46 & -1.32 & 0.48 & -0.91 & 0.36 & \\
\hline \multicolumn{9}{|l|}{ Composition } \\
\hline $\begin{array}{l}\text { Time } \\
\text { Canada }\end{array}$ & & -0.02 & 0.02 & -0.06 & 0.02 & -1.07 & 0.28 & -0.4 \\
\hline $\begin{array}{c}\text { Overall Trait } \\
\text { EI }\end{array}$ & 15 & & & & & & & \\
\hline Intercept & & 4.99 & 0.23 & 4.54 & 5.45 & 21.64 & $<.001 * * *$ & \\
\hline Gender & & 0.31 & 0.27 & -0.21 & 0.83 & 1.16 & 0.25 & \\
\hline \multicolumn{9}{|l|}{ Composition } \\
\hline $\begin{array}{l}\text { Time } \\
\text { Wellbeing }\end{array}$ & 9 & -0.03 & 0.01 & -0.06 & -0.00 & -2.29 & $0.02 *$ & -1.02 \\
\hline Intercept & & 5.62 & 0.59 & 4.46 & 6.78 & 9.48 & $<.001 * * *$ & \\
\hline Gender & & 0.28 & 0.67 & -1.03 & 1.59 & 0.42 & 0.67 & \\
\hline \multicolumn{9}{|l|}{ Composition } \\
\hline Time & & -0.04 & 0.02 & -0.09 & 0.00 & -1.82 & 0.07 & -0.73 \\
\hline Self-Control & 9 & & & & & & & \\
\hline Intercept & & 4.90 & 0.39 & 4.13 & 5.67 & 12.44 & $<.001 * * *$ & \\
\hline Gender & & 0.18 & 0.44 & -0.70 & 1.05 & 0.39 & 0.69 & \\
\hline \multicolumn{9}{|l|}{ Composition } \\
\hline Time & & -0.06 & 0.02 & -0.09 & -0.03 & -3.70 & $<.001 * * *$ & -1.14 \\
\hline Emotionality & 10 & & & & & & & \\
\hline Intercept & & 5.16 & 0.31 & 4.56 & 5.77 & 16.68 & $<.001 * * *$ & \\
\hline Gender & & 0.38 & 0.35 & -0.31 & 1.07 & 1.07 & 0.28 & \\
\hline \multicolumn{9}{|l|}{ Composition } \\
\hline $\begin{array}{l}\text { Time } \\
\text { Sociability }\end{array}$ & 9 & -0.05 & 0.01 & -0.07 & -0.02 & -3.72 & $<.001 * * *$ & -1.06 \\
\hline Intercept & & 5.42 & 0.21 & 5.02 & 5.83 & 26.03 & $<.001 * * *$ & \\
\hline Gender & & -0.36 & 0.24 & -0.83 & 0.11 & -1.50 & 0.13 & \\
\hline Composition & & & & & & & & \\
\hline Time & & -0.03 & 0.01 & -0.05 & -0.02 & -3.96 & $<.001 * * *$ & -0.6 \\
\hline
\end{tabular}


Table 3

Meta-regression Analyses examining the Interaction between Gender and Time on Trait EI Scores

\begin{tabular}{|c|c|c|c|c|c|c|c|}
\hline & $\boldsymbol{k}$ & $\beta$ & $S E$ & $95 \% L$ & $95 \% U$ & $Z$ & p-value \\
\hline \multicolumn{8}{|c|}{ Overall Trait EI 60} \\
\hline Intercept & & 4.66 & 0.63 & 3.42 & 5.89 & 7.38 & $<.001 * * *$ \\
\hline Gender Composition & & -0.62 & 0.81 & -2.21 & 0.97 & -0.76 & 0.45 \\
\hline $\begin{array}{l}\text { Country (reference } g \\
\text { roup = Australia) }\end{array}$ & & & & & & & \\
\hline USA vs Australia & & 0.32 & 0.67 & -1.00 & 1.63 & 0.47 & 0.64 \\
\hline Canada vs Australia & & 0.29 & 0.69 & -1.05 & 1.64 & 0.42 & 0.67 \\
\hline UK vs Australia & & -0.09 & 0.71 & -1.48 & 1.30 & -0.13 & 0.90 \\
\hline Time & & -0.02 & 0.05 & -0.12 & 0.08 & -0.41 & 0.68 \\
\hline Gender x Time & & 0.02 & 0.27 & -0.50 & 0.55 & 0.09 & 0.93 \\
\hline Wellbeing & 26 & & & & & & \\
\hline Intercept & & 5.42 & 0.34 & 4.75 & 6.08 & 16.01 & $<.001 * * *$ \\
\hline Gender Composition & & -0.70 & 0.48 & -1.66 & 0.25 & -1.44 & 0.15 \\
\hline USA vs Australia & & -0.09 & 0.36 & -0.79 & 0.61 & -0.25 & 0.80 \\
\hline Canada vs Australia & & 0.04 & 0.36 & -0.66 & 0.74 & 0.12 & 0.91 \\
\hline UK vs Australia & & -0.58 & 0.36 & -1.29 & 0.13 & -1.60 & 0.11 \\
\hline Time & & -0.05 & 0.02 & -0.10 & -0.01 & -2.33 & $<.05^{*}$ \\
\hline Gender x Time & & 0.47 & 0.16 & 0.16 & 0.77 & 2.99 & $<.01 * *$ \\
\hline Self-control & 26 & & & & & & \\
\hline Intercept & & 4.47 & 0.37 & 3.75 & 5.19 & 12.14 & $<.001 * * *$ \\
\hline Gender Composition & & -0.27 & 0.53 & -1.31 & 0.78 & -0.50 & 0.62 \\
\hline USA vs Australia & & -0.02 & 0.39 & -0.78 & 0.74 & -0.05 & 0.96 \\
\hline Canada vs Australia & & 0.03 & 0.39 & -0.73 & 0.79 & 0.08 & 0.93 \\
\hline UK vs Australia & & -0.44 & 0.39 & -1.22 & 0.33 & -1.12 & 0.26 \\
\hline Time & & -0.06 & 0.02 & -0.11 & -0.01 & -2.44 & $<.05^{*}$ \\
\hline Gender x Time & & 0.41 & 0.17 & 0.07 & 0.75 & 2.40 & $<.05^{*}$ \\
\hline Emotionality & 29 & & & & & & \\
\hline Intercept & & 5.03 & 0.30 & 4.44 & 5.61 & 16.92 & $<.001 * * *$ \\
\hline Gender Composition & & 0.07 & 0.43 & -0.77 & 0.92 & 0.17 & 0.86 \\
\hline USA vs Australia & & -0.13 & 0.31 & -0.73 & 0.48 & -0.41 & 0.68 \\
\hline Canada vs Australia & & -0.01 & 0.31 & -0.62 & 0.60 & -0.03 & 0.97 \\
\hline UK vs Australia & & -0.25 & 0.32 & -0.88 & 0.37 & -0.79 & 0.43 \\
\hline Time & & -0.05 & 0.02 & -0.09 & -0.01 & -2.39 & $<.05^{*}$ \\
\hline Gender x Time & & 0.24 & 0.14 & -0.03 & 0.51 & 1.73 & 0.08 \\
\hline Sociability & 26 & & & & & & \\
\hline Intercept & & 4.87 & 0.24 & 4.40 & 5.34 & 20.12 & $<.001 * * *$ \\
\hline Gender Composition & & -0.71 & 0.36 & -1.41 & -0.01 & -2.00 & 0.05 \\
\hline USA vs Australia & & -0.07 & 0.26 & -0.57 & 0.43 & -0.28 & 0.78 \\
\hline Canada vs Australia & & 0.03 & 0.26 & -0.47 & 0.53 & -0.12 & 0.90 \\
\hline UK vs Australia & & -0.23 & 0.26 & -0.73 & 0.28 & -0.87 & 0.39 \\
\hline
\end{tabular}




\begin{tabular}{lllllll} 
Time & -0.03 & 0.02 & -0.06 & 0.00 & -1.88 & 0.06 \\
Gender x Time & 0.20 & 0.12 & -0.03 & 0.43 & 1.74 & 0.08 \\
\hline
\end{tabular}




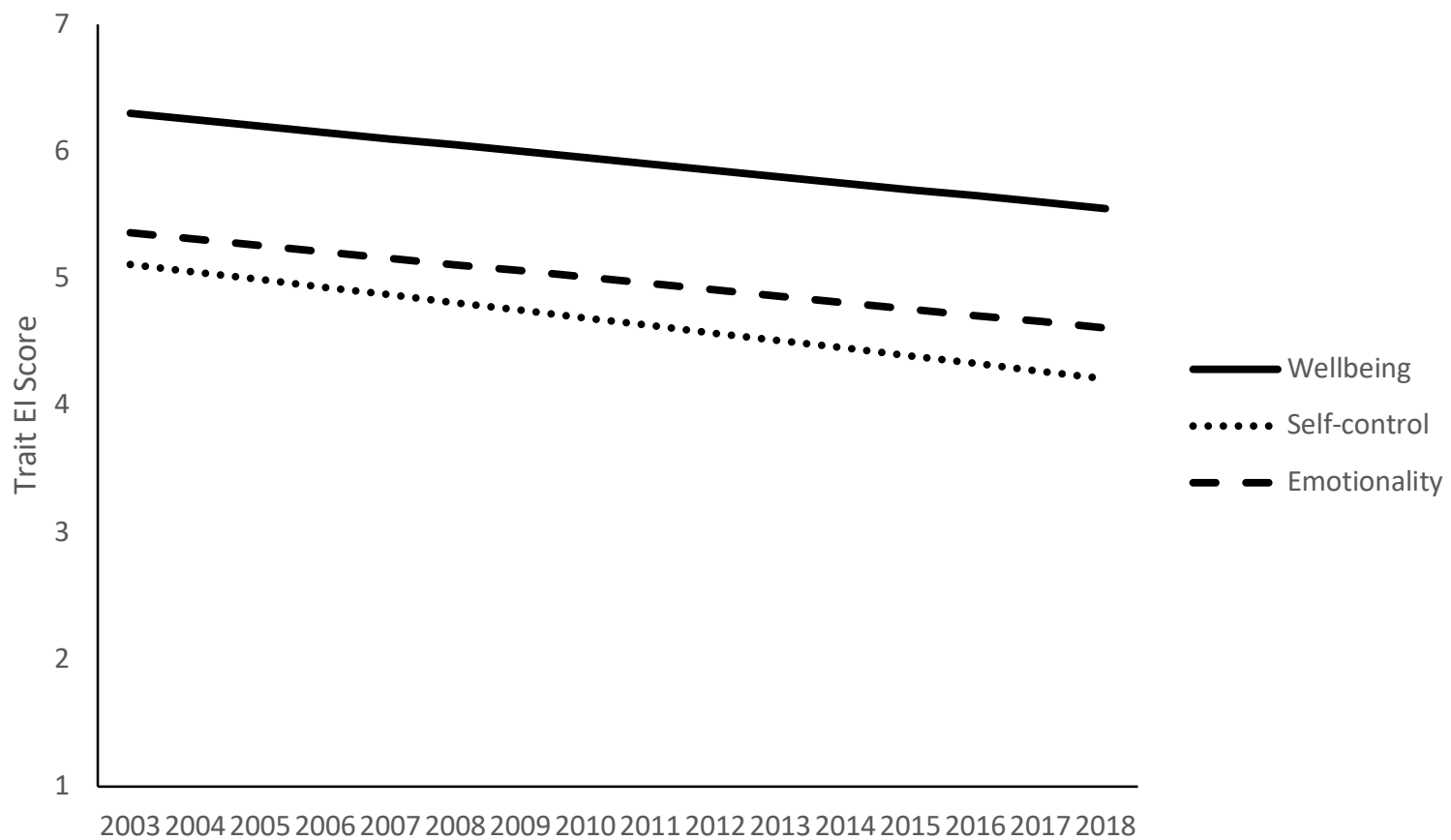

Figure 1. Trait EI scores with time. 